\title{
O STOFFWECHSEL COMO PRIMEIRO GESTO DE LIBERDADE DA VIDA SEGUNDO HANS JONAS
}

\author{
Leandro Sousa Costa ${ }^{1}$ \\ Universidade Estadual do Paraná (UNESPAR) \\ (D) https://orcid.org/0000-0002-2427-3324 \\ Leonardo Nunes Camargo ${ }^{2}$ \\ Pontifícia Universidade Católica do Paraná (PUC/PR) \\ (iD) https://orcid.org/0000-0002-3370-1327
}

\section{RESUMO:}

As considerações que faremos neste artigo vai analisar como o metabolismo se torna um mecanismo que representa o primeiro gesto de liberdade da vida na filosofia de Hans Jonas. A centralidade da discussão está no fato de que a vida é um processo de manutenção de si onde a liberdade está presente desde as estruturas mais simples do organismo às mais desenvolvidas. O nosso objetivo é o de mostrar, a partir de uma análise das ideias de liberdade e necessidade, como a vida se abre para uma transcendência ou, tecnicamente falando, para uma nova ontologia.

PALAVRAS-CHAVE: Metabolismo; Liberdade; Hans Jonas; Vida.

\section{THE STOFFWECHSEL AS FIRST GESTURE OF FREEDOM OF LIFE BY HANS JONAS}

\section{ABSTRACT:}

The considerations that will do in this article are going to analyze how the metabolism becomes mechanism that represents the first gesture of freedom of life, in Hans Jonas' philosophy. From this perspective this discution is in fact that life is a self-maintenance process where freedom shows up since the simplest structures of the organism to the most developed ones. Our goal is showing, from analyzes of the ideia of freedom and necessity, how life open it self to transcendence or, technically speaking, to new ontology.

KEYWORDS: Metabolism; Freedom; Hans Jonas; Life.

\footnotetext{
${ }^{1}$ Professor da Universidade Estadual do Paraná (UNESPAR), Paraná - Brasil. Doutorando em Filosofia pela Pontifícia Universidade Católica do Paraná (PUC/PR), Paraná - brasil. Email: leandro_kallas@hotmail.com

${ }^{2}$ Mestre em Filosofia pela Pontifícia Universidade Católica do Paraná (PUC/PR), Paraná brasil. Email: leonardo_bigmusic@yahoo.com.br

O stoffwechsel como primeiro gesto de liberdade da vida segundo Hans Jonas - Leandro Sousa Costa; Leonardo Nunes Camargo
}

Griot : Revista de Filosofia, Amargosa, Bahia - Brasil, v.15, n.1, p.128-145, junho/2017

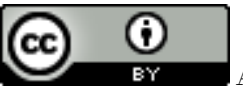




\section{Introdução}

Há um movimento significativo, por parte dos filósofos contemporâneos, em colocar o tema da vida na pauta de suas discussões, principalmente quando essa mesma vida é capturada, orientada e modificada pela técnica. O que é a vida? Uma pergunta simples, mas que suscita discussões amplas, muitas vezes acaloradas - especialmente quando envolvemos uma perspectiva religiosa - e que pode ser respondida de múltiplas maneiras a depender da área do conhecimento que estamos inscritos ao olhar para a questão. Nesse sentido, podemos notar que a tentativa de responder tal questionamento está atrelada ao modo de ser do humano. No entanto, nesse mesmo modo ser, há uma questão fundamental envolvida, a liberdade. Talvez nunca tenhamos parado para pensar que a liberdade pode estar presente até nas estruturas vivas mais simples.

As breves considerações que faremos aqui vai analisar como o metabolismo se torna um mecanismo que representará o primeiro gesto de liberdade da vida na filosofia de Hans Jonas. A vida é um processo de manutenção de si onde a liberdade está presente desde as estruturas mais simples do organismo. O nosso objetivo é o de mostrar, a partir de uma análise das ideias de liberdade e necessidade, como a vida se abre para uma transcendência ou, tecnicamente falando, para uma nova ontologia.

$\mathrm{O}$ texto se estrutura em três momentos. No primeiro vamos ver como o conceito de liberdade e os graus de desenvolvimento das funções dos organismos se traduzem como ideias fundamentais para a explicação da vida. Em seguida veremos que o metabolismo será tomado como característica básica e definidora da vida, pois é nesse processo simples que a liberdade se manifesta pela primeira vez diante de um espaço infinito de possibilidades, onde a pura matéria é a única coisa que existe e predomina. O terceiro momento vai mostrar que o movimento de desprendimento da vida das estruturas materiais a torna livre e por isso há um autotranscendimento que a coloca em contato com o mundo. A vida é colocada em um novo patamar na história, completamente desprovida de metafísica e causadora de si própria, pois ela busca, diante das ameaças, formas para se manter.

O homem não é um ser isolado, mas está em relação direta com os demais seres. A diferença se localiza no grau de desenvolvimento de funções e aptidões do organismo e, por conseguinte, de liberdade que o torna mais responsável pela vida como um todo. 


\section{Liberdade característica essencial da vida}

O conceito de liberdade, como elemento para interpretação da vida, é o auge da filosofia do organismo proposta por Hans Jonas ${ }^{3}$ que fez desse conceito uma espécie de "fio de Ariadne" da sua biologia filosófica. Vemos, em toda sua obra, que esse conceito se tornou essencial para a explicação da vida - dos instantes iniciais de seu surgimento às complexas formas assumidas pelas estruturas orgânicas ao longo da história de seu desenvolvimento.

De acordo com Jonas, no reino da vida, existe uma sucessão de níveis que são dispostos pela liberdade e isso nos permitirá, na perspectiva jonasiana, articular uma reflexão consistente sobre a vida. O filósofo, ao tratar do problema da vida, elege a liberdade como noção central de sua reflexão e, por isso, ela se torna, tecnicamente falando, um conceito-guia de sua nova ontologia. No texto $O$ princípio vida, Jonas nos apresenta:

No conceito de liberdade nós temos um conceito-guia capaz de orientar-nos na tarefa de interpretar a vida. O mistério do vir-aser em si é para nós inacessível. Por isso ele continua a ser uma suposição - para mim pessoalmente uma forte hipótese - que já o princípio que fundamenta a transição de substância sem vida para substância viva foi uma tendência nas profundezas do próprio ser designada por esta palavra. Mas de certo, logo o conceito encontra seu lugar na descrição da estrutura mais elementar da vida. Por conseguinte "liberdade" neste sentido descritivo, é um traço ontológico fundamental da vida em si; e também, como se comprova, o princípio contínuo - ou pelo menos o resultado constante - do seu avanço para graus mais elevados, onde a cada passo liberdade se constrói sobre liberdade, liberdade superior sobre liberdade inferior, liberdade mais rica sobre liberdade mais simples: em termos do conceito de liberdade o todo da evolução pode ser interpretado de uma maneira convincente (...); e a tarefa da biologia filosófica seria acompanhar o desenvolvimento deste germe de liberdade nos graus ascendentes do desenvolvimento orgânico (JONAS, 2004, p.106).

Nesse sentido, a postura assumida pelo pensador traz à tona a hipótese de que quanto mais complexo é um organismo mais liberdade ele terá. De acordo com Oliveira, "Jonas alarga o sentido da liberdade e a torna útil para interpretar a própria emergência e evolução da vida" (2015, p. 22). Não obstante, a liberdade, nesse novo contexto, deixa de ser uma característica exclusivamente humana e se torna um modo de ser próprio do

\footnotetext{
${ }^{3}$ De acordo com Fonseca, a partir do conceito de liberdade, "Jonas começa a revelar toda a originalidade de sua formulação, pois, não apenas ele atribui a liberdade às formas mais elementares da vida, como identifica essa primeira manifestação da liberdade a mais elementar atividade realizada por todo ser-vivo: o metabolismo" (2009, p. 179-180).
} 
organismo, isso se dá pelo fato de que o ser orgânico se atualiza constantemente pelo processo do metabolismo. Sendo assim, é possível notar que todo ser vivo, organicamente falando, tem a liberdade prefigurada em sua constituição e nos parece que essa postura é unânime por parte dos interpretes do autor.

\begin{abstract}
A liberdade agora não deve ser entendida mais como autodeterminação ou capacidade racional de escolha, mas como uma espécie muito própria de autocausalidade da vida, ou seja, como é causa de si mesma, a vida irrompe (como um acontecimento, ou seja, uma possibilidade no meio de infinitas possibilidades) no seio do não vivo (OLIVEIRA, 2015, p.28).
\end{abstract}

$\mathrm{O}$ surgimento da vida enquanto um acontecimento parte de uma escolha da própria vida, uma decisão que a mesma teve de tomar a fim de manter sua "sobrevivência". Através de uma ação primária, a substância viva ao se separar da interação geral das coisas da natureza, isto é, ao se desprender da matéria inerte, introduziu no mundo a tensão entre ser e não ser. Com essa escolha (ação primária) surge uma série de consequências que a vida terá que conviver, contradições que, até então, eram impostas apenas ao ser humano, como autonomia e dependência, vida e morte, relação e isolamento, eu e mundo, entre outros ${ }^{4}$.

A vida está marcada pela liberdade (ou seja, ela escolhe viver, dá o "sim" necessário para continuar a existir) e pela necessidade (caso a vida não quisesse viver, não optasse pelo sim, ela teria escolhido a morte, sua negação). A cada novo estágio que a vida opta por um sim, mais livre ela se torna, entretanto, junto com sua possibilidade de conquista há, em mesmo grau, o risco de fracasso, pois, "onde habita a liberdade também cresce o perigo" (OLIVEIRA, 2015, p. 23).

No prefácio de The Phenomenon of Life: toward a philosophical a biology, Jonas afirma que a liberdade já se encontra no substrato básico da vida, ou seja, o metabolismo. Liberdade nessa camada básica da história da vida representa o desprendimento que o organismo (forma viva) tem em relação à matéria. Essa liberdade nasce no metabolismo como independência do orgânico para com a matéria e termina nos níveis mais elevados da evolução orgânica, ou seja, passa pela imediaticidade das

\footnotetext{
${ }^{4}$ A polaridade fundamental, que Jonas considera, é a entre ser e não ser. O organismo deve constantemente afirmar sua identidade, fazendo um esforço constante para adiar sua contradição eminente, o não ser, uma vez que, este é a regra das coisas do universo. Entretanto, apesar de todo esforço que o organismo empreender ao se opor a sua contradição, no fim ele sucumbirá perante a morte. Dessa forma, a mortalidade torna-se característica essencial da própria vida.
} 
plantas, pelas capacidades de sensação, movimento e emoção dos animais, e chega aos seres humanos ${ }^{5}$, último estágio da escala evolutiva de Jonas.

Foi através do metabolismo que as primeiras formas de vida se afirmaram diante do não ser. $\mathrm{O}$ autor considera que se no metabolismo existe essa forma independente de auto-organização da matéria em direção a manutenção de sua própria existência é porque essa vida escolheu ser vida. Nas palavras de Oliveira, "essa "decisão" constitui-se também como uma "escolha" da vida por si mesma, pela sua preservação" (2015, p. 23). Nesse caso, a liberdade como metabolismo se revela como "um poder da forma orgânica, o poder de mudar sua matéria, mas que, ao mesmo tempo implica também a inevitável necessidade de fazer exatamente isto" (JONAS, 2004, p. 107). A vida é livre e como tal "carrega nos ombros o fardo da necessidade" (JONAS, 2004, p. 14). Trata-se de uma "liberdade dialética" (JONAS, 2004, p. 106): ao mesmo tempo em que é livre, a vida também é obrigada à liberdade, na medida em que precisa intercambiar com o ambiente para que possa continuar vivendo. Desse modo, a atividade metabolizante torna-se, no pensamento de Jonas, a característica fundamental da existência orgânica.

Duas características da vida são essenciais para entendermos porque é um risco existir e porque ela é efêmera. Ambas as características estão ligadas a ideia de morte, são: a precariedade e a dependência. A vida, quando se tornou vida, trouxe junto consigo, como sua condição, a morte, sua negação; por mais que a vida escape da sua contradição, em determinado momento ela sucumbirá, este é o aspecto precário que a vida deve enfrentar. Em relação a dependência, mesmo tendo se desprendido da matéria, ela ainda depende totalmente de materiais inorgânicos e, por consequência, sempre precisará recorrer a certos materiais para manter sua sobrevivência. A audácia da liberdade da forma viva carregou consigo o fardo da necessidade.

Para Oliveira, "a vida, para afirmar-se, experimenta a liberdade como uma abertura correlacional entre o organismo e o mundo" (2015, p. 25). E é através dessa mesma liberdade que matéria e espírito se unem como partes de um único organismo. De acordo com Jonas, foi através dela que processos químicos, como o metabolismo, ocorrem e deram início a vida. Sobre o metabolismo foram consolidadas todas as outras etapas da liberdade, e todas elas mantém relações com o metabolismo. Portanto, "vida é, para Jonas, a história da liberdade" (OLIVEIRA, 2015, p. 29) no sentido de que a todo instante o organismo está decidindo sobre sua permanência ou não no âmbito da natureza.

A liberdade que a forma viva adquiriu possui uma identidade orgânica, identidade essa que não pode ser prevista nem descrita por

\footnotetext{
${ }^{5}$ Para Jonas, o ser humano é o auge do desenvolvimento das capacidades evolutivas da vida, dessa forma, é nele que estão os maiores perigos que ela deve enfrentar, sem dúvida, a técnica é a que mais a ameaça.
}

O stoffwechsel como primeiro gesto de liberdade da vida segundo Hans Jonas - Leandro Sousa Costa; Leonardo Nunes Camargo 
aspectos puramente materiais no espaço e tempo, é graças a sua atividade metabólica (processo contínuo de troca de matéria) que a forma viva não deixa à disposição nenhuma referência de identidade exterior. Segundo Jonas, "tal identidade interior está implícita na aventura da forma, involuntariamente sendo induzida de seu testemunho morfológico exterior, o único acessível a observação" (JONAS, 2004, p. 105). Mas, como podemos conhecer nossa identidade orgânica?

De acordo com Jonas, o observador despreparado não tem condições de responder e compreender tal questionamento, pois o aspecto essencial para tal entendimento é estar preparado através da própria vida. Nós só podemos falar da vida e entendê-la, porque a possuímos, somos devidamente preparados por aquilo que somos, temos uma vantagem sobre o grande arquiteto do universo, e essa vantagem é porque temos um corpo vivo.

\footnotetext{
Dele se exige o ser orgânico com sua experiência própria, para que esteja em condições de deduzir aquela "consequência" que de fato ele tira continuamente, e esta é a vantagem, tão teimosamente negada e caluniada, da história do conhecimento - a vantagem de termos um corpo, ou de sermos um corpo. [...] Só por meio da interpolação da identidade interior, que assim se torna possível, é que o fato meramente morfológico da continuidade metabólica é compreendido como ato incessante, isto é, a continuidade é compreendida como autocontinuação (JONAS, 2004, p. 105).
}

O surgimento do conceito de si-mesmo que podemos analisar em qualquer forma de vida, nos sugere que a identidade entrou no mundo junto com a vida, e também sua capacidade de autoisolar-se do mundo. "A mesmidade do organismo é caracterizada pela individualidade e heterogeneidade radical em meio a um universo de seres homogeneamente relacionados entre si" (JONAS, 2004, p. 105). A identidade orgânica é construída de momento a momento, regida pela polarização entre mundo e vida, tal perspectiva nos permite afirmar que essa característica se fundamenta a partir da noção de liberdade que faz com que a vida se conserve com ousadia e precariedade.

Dessa forma, o próprio ser orgânico passa a ser pensado como uma atividade. Ora, tal atividade está ligada ao conceito de vida e, dessa forma, inaugura-se uma nova filosofia voltada ao organismo - tanto como espírito quanto como matéria. Segundo Jonas, a vida é um modo de ser e o organismo vivo é a parte visível do universo na qual esse modo de ser se realiza, ou seja, é no corpo vivo que o ser se manifestará efetivamente. 


\section{Metabolismo: substrato básico da vida}

Em sua obra Wissenschaft als persönliches Erlebnis de 1987, o autor alemão, afirma que o metabolismo é a camada básica e definidora da vida, uma espécie de condição comum a todo ser vivo. O metabolismo na filosofia de Hans Jonas se transforma na essência da vida. Se o traduzirmos simplesmente como troca de matéria, seu significado ficará incompleto. Algumas questões surgem a partir dessa consideração inicial, quais sejam: como um processo de troca de matéria como o metabolismo pode descrever o organismo e a vida? Ou ainda, como o metabolismo, extrato básico da existência da vida, é capaz de reconhecer a dimensão da liberdade? Como a liberdade se manifesta através de um processo químico que ocorre em nossos corpos? Um possível seguimento de análise tem por base a ideia de que Jonas quer demonstrar que é num processo simples, como o metabolismo, que a liberdade se manifesta pela primeira vez diante de um espaço infinito de possibilidades, onde a pura matéria é a única coisa que existe e predomina. Estes questionamentos ainda estão relacionados com a noção de identidade da forma orgânica, e é isto que diferencia um organismo vivo das demais formas físicas que conhecemos no universo.

O ser vivo, enquanto um aglomerado de matéria extensa, não é simplesmente uma matéria, na qual podemos tocar e que possui uma identidade fixa e imutável, como são com as coisas físicas. O ser vivo é uma forma organizada da matéria e ao mesmo tempo é independente deste aspecto material, pois constitui através de um processo contínuo de trocas sua própria identidade.

Em sua carta de 25 de fevereiro de 1944, destinada a sua esposa Lore Jonas, durante a Segunda Guerra Mundial, presente em sua obra Memorias, Jonas escreve que as coisas materiais possuem identidades simples e imediatas, completamente vazias, dessa forma sua identidade não se transmuta ao longo do tempo. De um ponto de vista gnosiológico, podemos afirmar uma identidade na partícula material, ou seja, graças a essa persistência ao longo do espaço e do tempo em afirmar sua identidade que permanece inalterada. Pelo fato de a identificarmos nas várias regiões do espaço que ela pode ocupar, podemos afirmar uma identidade na matéria, "sua trajetória ininterrupta no contínuo espaço-temporal é aqui o único critério de identidade" (JONAS, 1998, p. 26).

Qualquer partícula de matéria, independentemente de sua posição espaço temporal, possui uma auto-identidade vazia em relação à substância, só pode ser afirmada e percebida devido a sua persistência e duração ao longo do tempo, sua mesmidade é uma função da continuidade das dimensões espaciais e temporais; sua forma é um acidente, totalmente dependente da matéria, portanto sem uma realidade própria. São alguns fatores, como a duração, a mesmidade e a perseverança da matéria, que 
criam certa identidade de um corpo material, mas que não deve ser confundido com a identidade orgânica.

A mudança que uma partícula traça ao longo do espaço nos permite identificá-la, saber seu estado original quando ela se movimenta, se a partícula está aqui ou ali, mesmo que ela se desloque abruptamente do seu espaço original podemos identificá-la, devido a sua trajetória traçada ao longo do caminho percorrido. De acordo com Jonas, esse corpo material pode ser facilmente identificado, porque sua progressão pode ser analisada e estudada facilmente.

A identidade do ser vivo se constitui através de uma atividade incessante, resultado de uma autoconstituição e autorrenovação de sua forma, que vão se originando mediante sua atividade. Segundo Jonas,

\footnotetext{
...sua existência é uma função e não substância; sua duração é acontecimento e não precisamente perseverança, uma vez que a perseverança é abandonada uma e outra vez num processo de autogeração. (...) A identidade fixa, material, da partícula, se opõe a identidade dinâmica, funcional do ser vivo (JONAS, 2005, p. 381-382).
}

Desta maneira, a existência do ser orgânico não é algo dado, como acontece num corpo material, mas resultado de sua própria geração. $\mathrm{O}$ ser vivo está a todo momento se constituindo e se autogerando, ou seja, ele está em constante atividade. Para entendermos a identidade do ser vivo, precisamos lembrar a inversão ontológica que Jonas propôs, ou seja, o fato de que a forma é um caráter essencial da vida e não a matéria. Do ponto de vista do metabolismo, a forma está relacionada com a essência e a matéria se tornou o acidente do ser, em outras palavras, na configuração orgânica do ser, o elemento orgânico deixa de ser substância e passa a ser substrato. A liberdade está, nesse caso, ligada à forma e essa, encontra-se entrelaçada com o metabolismo.

O caráter da autonomia da forma viva se revela e se constitui não de uma só vez, ou seja, ela não recebe todo seu conteúdo material em um único momento da sua existência. Sua estrutura é constituída por momentos de trocas de matérias com o mundo no qual ela pertence, num movimento constante de receber e eliminar aquilo que lhe é necessário. Contudo, ao longo desse processo, a forma viva continua sendo ela mesma e se moldando nos traços de um ser orgânico. Segundo Jonas, "a forma viva é apenas um ponto de transição da matéria que a atravessa segundo suas próprias leis e cuja unidade aparente não é mais que um estado configurativo de sua diversidade" (JONAS, 2005, p. 383).

Nesse novo nível da vida, a forma é o estágio em que a matéria passa a fazer parte da própria vida, é ela que atrai e expulsa a própria matéria de si mesma em relação ao mundo. Enquanto no corpo material a forma nada mais é que um estágio de troca da matéria permanente, na forma viva ela 
atua de maneira organizativa, mesmo quando seus conteúdos materiais não sofrem mutações no ser e continuam sendo idênticos. Sendo assim, mesmo a forma sendo um ponto de passagem da matéria, devemos afirmar que, a sucessão de conteúdos materiais que se configuraram sucessivamente, são fases transitórias em um processo da forma.

A vida também se enquadra na história do universo material, porém trata-se de um estado muito efêmero, ao mesmo tempo, um paradoxo, a matéria se converte em algo fundado nela mesma, ou seja, a forma viva. A matéria sai do campo quantitativo e se transfere à esfera qualitativa. Segundo Jonas, ela "transcende a si mesma" (JONAS, 2005, p. 384). Diante da autonomia que a forma exerce em relação a matéria, não se trata de uma separação radical entre ambas, pelo contrário, o organismo é sempre forma da diversidade da matéria. E é justamente nisso que se encontra a sua liberdade.

Sobre a identidade orgânica ainda temos que mencionar o fato de que, se compararmos e afirmarmos a identidade apenas de um ponto de vista material, não seria possível afirmar uma identidade nos corpos orgânicos. Mesmo os seres mais simples e primitivos mudam sua identidade material constantemente, tornando-se novos seres materiais a cada momento, entretanto, são capazes de manter a mesma identidade ao longo dessas trocas. Identidade orgânica deve ser sempre relacionada com o metabolismo. Jonas ao observar as bactérias ${ }^{6}$, assim descreve o problema da identidade orgânica.

Como um grande corpo complexo (algo que a própria bactéria já é) o organismo apresentaria os mesmos traços gerais que outros agregados. Mas tanto dentro como fora dele seriam observáveis processos especiais que tornam sua unidade fenomênica ainda mais questionável do que a dos corpos comuns e que anulariam quase por completo sua identidade material no decorrer do tempo. Refiro-me ao seu metabolismo, sua troca de matéria com o ambiente (JONAS, 1998, p. 22).

A função do metabolismo, além da pura e simples troca de matéria com o meio ambiente, é um processo contínuo que autoconstitui o organismo na forma de uma atividade desempenhada pela própria vida como sua característica central. Dessa forma, para tratarmos da identidade orgânica dos seres vivos, devemos considerar que um organismo, por mais primitivo que seja, não permanece com os mesmos elementos materiais por

\footnotetext{
${ }^{6}$ É notável que em certos momentos Jonas utiliza ora o termo ameba ora bactéria, o fato é que ambos representam bem esse modelo primitivo de organismo no qual o autor se refere, e que ajudam a ilustrar o problema sobre a identidade orgânica. Segundo Frogneux, a ameba representa o arquétipo primordial para o modelo orgânico de Jonas, ela é "o paradigma do vivente inferior" (FROGNEUX, 2001, p.178).
} 
um longo período, ao contrário, a todo instante, ele incorpora novos elementos e os elimina.

Essa constante mudança de matéria que o metabolismo é responsável em realizar num ser vivo, coloca a seguinte questão: como um ser que muda constantemente seu conteúdo material pode ser o mesmo? Como podemos afirmar uma identidade em algo que não permanece o mesmo? A reposta é que a forma viva, como sendo a essência do organismo, acompanha o fluxo de mudanças da matéria, ou seja, a essência orgânica do ser vivo permanece sempre a mesma. Segundo Jonas, essa forma viva que acompanha a matéria, que permanece no ser vivo, é uma conquista da liberdade. O desafio de Jonas fica explícito aqui: pensar as contradições da liberdade humana no nível da vida, essa é a releitura biológica que o autor propõe quando escreve sua obra The Phenomenon of Life: toward a philosophical a biology.

Como podemos afirmar a autonomia da forma num ser vivente? A primeira ideia que precisamos levar em conta quando tratamos da forma viva é que ela é organizativa e ativa por si só, é a própria forma que realiza as trocas materiais com o meio ambiente, ela está em um constante autoconstituir-se. Jonas dá a seguinte definição para os organismos vivos em sua Memorias.

Unidades de matéria, que não são unidades na multiplicidade graças a observação, mas [unidades] por si mesmas; coisas, cujo ser coisa e ser tal [coisa] dependem e são continuamente mantidos por elas (entelecheia); formas que não são o resultado mas a causa (arche) de um determinado aglomerado material; unidade que se coloca a si mesma; forma que se auto integra (JONAS, 2005, p. 410).

A autointegração da vida nos leva ao conceito ontológico de indivíduo ( $c f$. JONAS, 2005, p. 410), que faltava para afirmarmos a identidade do orgânico, pois junto com o indivíduo ontológico está a existência subjetiva do próprio sujeito. A identidade orgânica está além do puro aspecto material, porque o organismo possui uma identidade funcional, que está ligada a sua identidade interna, ou seja, o organismo vivo possui uma existência subjetiva. Mesmo afirmando que no organismo exista uma interioridade que constitui a identidade do ser orgânico, para Jonas, não estamos tratando de uma entidade internamente separada, pelo contrário, é um processo de organização contínuo do organismo que se realiza no metabolismo.

Para Jonas, o mistério de onde e como surgiu a liberdade ainda é questionável, porém para o mesmo, a saída mais convincente é de que no momento da passagem da substância sem vida para a substância viva ela já estava presente. Ainda segundo o autor, a liberdade deve ser conferida como "um traço ontológico fundamental da vida em si" (JONAS, 2004, p. 106), 
ou ainda, um processo contínuo que se desenvolve em cada estágio do desenvolvimento do ser orgânico.

O conceito de metabolismo precisa ser complementado com a liberdade. Para Jonas liberdade absoluta é uma expressão incorreta, ela não existe para nenhum ser vivo, sempre estará acompanhada de um momento antitético. A liberdade está sempre acompanhada de "uma necessidade correlativa que lhe adere inseparavelmente como a própria sombra" (JONAS, 2004, p. 107). Essa sombra são as polaridades que acontecem na história da vida, a cada degrau que a liberdade avança na escala evolutiva as polaridades tendem a se acentuar no mesmo grau de intensidade.

\begin{abstract}
A liberdade se torna, paradoxalmente, algo obrigatório, pois o vivo, para continuar sendo vivo, necessita (é obrigado a) escolher a si mesmo, ou seja, implementar a saída de si em direção ao mundo que o cerca, em busca dos nutrientes de sua própria sobrevivência. $\mathrm{O}$ poder de transformar em seu próprio benefício esses elementos recolhidos no exterior está assinado no âmbito de uma necessidade absoluta de fazê-lo, dada a ameaça constante do não-ser que ele mesmo carregou para dentro da existência (OLIVEIRA, 2015, p. 24).
\end{abstract}

Esse caráter paradoxal que acompanha a liberdade, pode ser verificado no metabolismo, se por um lado sua função é a de um poder sobre a matéria, ou seja, o metabolismo pode mudar a constituição material de um organismo constantemente, por outro, essa mudança é uma obrigação sua, "seu poder é um dever, uma vez que o realizar identifica-se com o seu ser" (JONAS, 2004, p. 107). Dessa forma, o metabolismo se torna uma prioridade absoluta em relação ao ser vivo. Nas suas Cartas Formativas Jonas tenta esclarecer o paradoxo: se a liberdade ontológica que a forma viva adquiriu consiste em mudar sua substância material, para se afirmar como um ser vivo, e tal função ela pode desempenhar, constituindo assim o seu ser, torna-se sua obrigação realizar tais trocas com o meio ambiente, ela não pode não fazer, ela deve necessariamente agir de acordo com o seu ser (cf. JONAS, 2005, p. 272).

Jonas em The Phenomenon of life retoma o paradoxo, mas agora dirige-se ao metabolismo, e retoma um importante assunto que foi abandonado ao longo da tradição filosófica, a de que o poder implica um dever.

\footnotetext{
Porque sua "liberdade" é sua necessidade, o "poder" se transforma em "dever" quando o que importa é ser, e em toda vida é deste "ser" que se trata. O metabolismo, portanto, a capacidade que distingue o organismo, sua soberana primazia no mundo da matéria, é ao mesmo tempo sua forçosa obrigação. Podendo o que pode, ele não pode, entretanto, enquanto existir, não fazer o que pode. Possuindo o poder, tem que exercê-lo para existir, e não pode cessar de fazê-lo sem que
} 
cesse de existir: liberdade para o fazer, mas não para o omitir (JONAS, 2004, p. 107).

Dessa maneira ao passo que o metabolismo foi um degrau em direção às garantias de continuidade da vida e ao desprendimento da matéria, ele ainda necessita da mesma para exercer sua função no ser vivo. Esta sujeição à matéria é característica própria da vida, isso para mostrar que a liberdade é uma necessidade, e esta é a antinomia que acompanhará a vida em seus graus mais acentuados de desenvolvimento e que já está presente na camada mais básica da história do organismo.

A relação entre liberdade e necessidade não acontece apenas dentro do ser vivo, ou seja, a forma viva depende da matéria para realizar suas trocas, e esta matéria está fora de si, no mundo externo a ela. Dessa forma, de acordo com Jonas, a vida possui uma relação particular de dependência e poder com o mundo. Essa necessidade de renovar constantemente sua matéria faz com a vida se abra a realidade externa. $\mathrm{O}$ contato da vida com o mundo é intermediado pela própria experiência durante a troca de matéria da forma viva.

A vida possui necessidade do mundo, está relacionada com ele, depende dele, está disposta ao encontro dele, experimenta o mundo, e através dessa "experiência, possui o mundo" (JONAS, 2004, p. 108). O mundo torna-se elemento constitutivo da atividade orgânica, enquanto o ser vivo depender da matéria para se renovar, o mundo se abrirá para a forma viva a fim de suprir suas necessidades, que deve ser entendida aqui como carência ${ }^{7}$.

\section{A transcendência da vida: liberdade e necessidade}

A vida precisa ampliar seu horizonte de atuação, fazendo do mundo além de uma necessidade orgânica da matéria, uma fundamentação da liberdade material. Desse modo, podemos afirmar uma transcendência da vida, que vai além de sua relação consigo mesma, ou seja, ela "quer ultrapassar os próprios limites e abrir-se para o mundo" (OLIVEIRA, 2015, p. 23).

\footnotetext{
${ }^{7}$ Jonas se refere à carência como uma das propriedades do ser orgânico, como uma característica exclusiva da vida, portanto, não pertencente ao resto da realidade. De acordo com o autor, um átomo por ser um elemento auto-suficiente existe independentemente do que aconteça com o mundo a sua volta, entretanto, "a essência do organismo, ao contrário, inclui a não autarquia" (JONAS, 1998, p. 93). Por poder usar o mundo, a vida encontra sua polaridade, ou seja, sua necessidade, se ela pode atuar no mundo, ela deve, pois se não fizer pode deixar de existir. Dessa forma, a vida é dependente da sua própria ação. "A dependência que impera aqui é a dívida que a substância primordial assumiu quando, ao invés de permanecer na matéria inerte, se aventurou ao iniciar o caminho da identidade orgânica, uma identidade que se constitui a si mesma" (JONAS, 1998, p. 93).
} 
Neste autotranscender através da condição de necessidade fundamenta-se a transcendência essencial de toda vida, que nos estágios mais elevados lhe abre um mundo cada vez mais amplo. O ser dependente indica o campo de suas possíveis realizações, desta maneira criando a intencionalidade como um caráter básico de toda a vida (JONAS, 2004, p. 109).

Para entendermos a transcendência da vida precisamos considerar que junto com a carência, o interesse é um dos fundamentos desta autotranscendência, uma vez que ele é uma das antinomias da necessidade e da liberdade. De acordo com Comín, a liberdade deve ser entendida como "constante tensão e relação de reciprocidade com a necessidade" (2005, p. 45). Dessa forma, quando o organismo necessita de algo, e passa a ter interesse por aquilo, novos horizontes se abrem para que esta carência possa ser suprida. O próprio Jonas afirma, "quando falamos de transcendência da vida, queremos dizer que ela mantém um horizonte, ou horizontes, além de sua identidade puntiforme" (JONAS, 2004, p. 110).

Junto com essa transcendência e essa abertura ao mundo estranho na qual a liberdade ontológica passa a depender da matéria e juntas alcançam novos estágios e graus de ascensão de liberdade, precisamos considerar a dimensão da interioridade. Ela está presente nas ações que acontecem dentro do organismo, ela de certo modo, abriga o interesse absoluto do organismo em sua existência e sua vontade de preservação.

A autotranscendência pode ser entendida como um movimento compulsivo ligado à atividade, graças a uma necessidade orgânica, orientada para fora através de um lado passivo dessa transcendência, que são as sensações capturadas ao longo do processo. Esse processo "coloca a vida no estado de ser 'eletiva' e informada', em lugar de ser apenas uma cega dinâmica" (JONAS, 2004, p. 110). Desta maneira, a função da interioridade nessa etapa da autotranscendência da vida, é a de comunicação entre as coisas.

Este autotranscender da vida e sua abertura ao mundo, marcado pela necessidade e carência, além de se referir as necessidades do organismo em sua imediaticidade, ou seja, dos objetos que estão disponíveis e acessíveis no meio ambiente, para Jonas, junto com o auto-interesse espacial, "abre-se igualmente um horizonte temporal, que abrange não o presente exterior, mas sim o estar-eminente interior" (JONAS, 2004, p. 110). Este estar eminente é aquele momento futuro para onde a necessidade orgânica leva o organismo para suprir suas carências. Dessa forma, a vida passa a ser marcada tanto para frente como para fora.

$\mathrm{Na}$ transcendência da vida encontramos o essencial para a atividade metabólica, que Jonas traduz da seguinte forma:

Os dois horizontes para os quais a vida constantemente se transcende podem ser reduzidos à relação transitória da forma orgânica para com sua própria matéria. A orientação interior

O stoffwechsel como primeiro gesto de liberdade da vida segundo Hans Jonas - Leandro Sousa Costa; Leonardo Nunes Camargo 
para a fase imediatamente seguinte de um ser que precisa manter-se a si mesmo constitui o tempo biológico; a orientação exterior para o não-ele-mesmo igualmente presente que contém a matéria necessária para sua continuação constitui o espaço biológico (JONAS, 2004, p. 110 - 111).

Essas duas expressões utilizadas por Jonas, o espaço biológico e o tempo biológico, complementam nossa discussão a respeito da transcendência da vida.

O espaço biológico se refere ao espaço no qual a vida transcende e se abre, podendo ser entendida como a faculdade de ter o mundo, ou seja, é uma autotranscendência da própria vida em direção ao ambiente externo. $\mathrm{O}$ ser vivo, ao contrário da matéria pura e inerte, graças a sua necessidade de se auto-afirmar a cada instante, vai se moldando e abrindo-se ao mundo externo, nesse constante exercício, a vida além de fazer a experiência do mundo vai ao encontro com ele.

Graças a essa abertura ao mundo e ao mesmo tempo de possuí-lo, a liberdade pode se expressar em graus cada vez mais elevados, a partir de duas dimensões: a perceptiva e a ativa. Segundo Jonas, "o horizonte aberto significa afetividade tanto quanto espontaneidade, expor-se ao exterior não menos que chegar ao exterior: é só pelo fato de a vida ser sensitiva que ela pode ser ativa" (JONAS, 2004, p. 109). Dessa forma, "o espaço biológico é tudo aquilo sobre o que o organismo atua e percebe" (LOPES, 2014, p. 183).

A espontaneidade do organismo por estar relacionada com a autotranscendência da vida, e por ser um movimento para fora o ser vivo precisa suprir suas carências. Tanto a carência como o desejo e a vontade de poder caminham em função do interesse e da satisfação do ser vivo.

Porque carece e depende do mundo, ele se interessa pelo mundo; porque se interessa, ele busca o mundo de que carece; e no buscar vai além de si mesmo em direção a esse mundo. Assim, a forma viva está ligada (pela matéria) e referida (pela necessidade) ao mundo, isto é, o transcender está dado tendencialmente na indigência orgânica (LOPES, 2014, p. 183).

De certa maneira esse transcender da vida implica estar disposto a uma relação. Ao posso que através do metabolismo o organismo assimila o conteúdo externo a fim de suprir suas necessidades, esse mesmo ser vivo precisa dominar a natureza. Graças a essa abertura do organismo ao mundo, o ser vivo passa a reconhecer o outro. Dessa forma, se o metabolismo é a primeira característica da vida, ou seja, o primeiro passo que a forma viva dá em direção ao mundo externo a fim de inibir suas necessidades, graças a essa abertura, esse passo em direção ao que é estranho, o organismo passa a 
se relacionar, segundo Jonas, "viver é essencialmente estar relacionado com algo" (JONAS, 2004, p. 15).

O auto-isolamento (também característica do organismo) é muito mais uma necessidade da forma viva do que uma falta de relação com o mundo. Sem dúvida, a capacidade de isolamento e sua transcendência em direção ao mundo (ambiente) revela a dicotomia e a polarização da vida, que a acompanha desde seu surgimento, ou seja, estamos falando da antinomia entre eu e mundo.

Toda ação do organismo no mundo externo necessita de informações. O primeiro fator a enviar essas informações ao ser vivo são as sensações, elas permitem que a vida não siga simplesmente um dinamismo cego, mas pelo contrário, seja capaz de selecionar suas reais carências e de que seja informada. $\mathrm{O}$ próprio ato de procurar alimento faz com que a vida se torne discriminativa, o organismo precisa reconhecer o que pode e deve ser apropriado e assimilado. Até mesmo quando o ser vivo está ameaçado ele necessita de informações para se defender.

Precisamos lembrar que a vida não é marcada apenas pelos inimigos e adversidades que o organismo pode encontrar, ela também é representada por uma socialidade, ou seja, o autor defende que a mensagem transmitida também pode ser de outro ser que queria "ajudar", por exemplo, na captura de nutrientes para sua preservação. Jonas em um curso de $1966^{8}$, afirma que a existência com os outros é essencial ao indivíduo orgânico. A vida necessita de alguma espécie de trocas e comunicação entre os membros da espécie, nem que seja apenas para fins reprodutivos.

Mesmo com o papel que a socialidade desempenha na vida do ser vivo, o metabolismo ainda continua sendo a camada básica da existência da vida. Graças a ele, a vida encontra meios para se autotranscender para estágios mais elevados e complexos, a cada novo estágio mais liberdade e mais individualidade, sendo assim, mais mediação do organismo em relação ao mundo, novas carências e necessidades surgirão e se unirão a camada metabólica básica.

O indivíduo orgânico e sua capacidade de transcendência em relação ao mundo, não pode ser pensada apenas do ponto de vista espacial, ou seja, sua capacidade de ter o mundo, ela está ligada ao tempo biológico.

No horizonte do tempo, que marca a transcendência do orgânico e sua continuação, o futuro é mais fundamental que a historicidade vivida pelo ser orgânico, contudo não podemos descartar a vivência no passado e a memória, pois elas são essenciais para garantir a identidade, porém esse passado se transforma em condição para a continuidade interior do ser vivo. O futuro se abre como "impulso da vida" (JONAS, 2004, p. 111).

\footnotetext{
${ }^{8}$ Esse curso foi realizado entre os anos de 1966 e 1977, e encontra-se no Arquivo Hans Jonas na Universidade em Konstanz e tem como título Life and Organism.
} 
Ao contrário do sistema temporal linear que marca aquilo que foi, baseado no passado e voltado para o futuro, a vida sempre será o que ela é no presente e o que se prepara para ser, essa é a raiz teleológica do orgânico, ou seja, trata-se de um caráter dinâmico de uma maneira de ser, que de certa forma encontra-se com a identidade e a liberdade da forma em relação a matéria.

O tempo biológico está aberto à experiência orgânica, abrange algo que está por acontecer, ou seja, a cada momento num futuro próximo, a continuidade orgânica está disposta a satisfazer suas carências daquele momento. Assim, "a vida está voltada tanto para frente como para fora" (JONAS, 2004, p. 110). A transcendência temporal está voltada ao futuro, para o logo mais. Este não pode ser confundido com o tempo físico, pois para Jonas, no ser vivo os momentos temporais estão interligados pela interioridade orgânica, sendo assim, a vida só se volta para fora porque através de sua necessidade e liberdade ela precisa olhar também para frente (cf. JONAS, 2004, p. 110).

Portanto, foi graças a forma viva que a vida surgiu no universo, junto com ela, como vimos, veio os riscos e perigos que ameaçam sua existência. O metabolismo é apenas o primeiro passo da liberdade, após ele várias etapas surgirão ao longo da vida, e tornaram a vida cada vez mais livre e dinâmica, até chegarmos ao ser humano, ápice do desenvolvimento do ser orgânico, onde há mais liberdade e maior risco. Por ser o auge da escala evolutiva de Jonas, o homem se torna o principal agente de responsabilidade, além de ter o dever de zelar e cuidar da vida desde as estruturas mais simples que ela for capaz de se manifestar.

\section{Considerações finais}

É da liberdade que nasce o perigo e, como vimos, a forma viva, ao se desprender da matéria, trouxe junto com ela o risco e a ameaça de morte. Além disso, ao se afirmar num horizonte de transcendência, a vida ficou marcada por certas contradições (liberdade e necessidade; autonomia e dependência; relação e isolamento; natureza e mundo) que, antes de Jonas, estavam ligadas apenas ao ser humano, mas, a partir de então, se tornaram polaridades inerentes a todo ser vivo. Algumas manifestadas mais intensamente em alguns seres vivos, mas todos, de alguma forma, estão ameaçados pelo não ser.

A liberdade que cresce exponencialmente até chegar ao ser humano e o torna agente da responsabilidade é a mesma que ameaça sua integridade para as gerações futuras e ameaça aniquilar a natureza como um todo, graças ao poder desenfreado que a técnica moderna possibilitou ao homem. Se a forma viva, através de um movimento livre e espontâneo, escolheu a vida, o homem, por possuir a mesma liberdade que possibilitou a ele - como todas as demais formas de vida - existir, deve usá-la para promover e 
proteger a vida, garantindo um futuro digno a todas as gerações, não somente à humanidade, mas a todos os seres vivos. 


\section{Referências bibliográficas:}

COMÍN, I. G. "Introducción a la edición española". In: Hans Jonas: poder o impotência de la subjeticidad. Tradução de Illana Giner Comin. Coleção pensamento Contemporâneo. Barcelona/Buenos Aires/México: Paidós, 2005, p.13-70.

FONSECA, F. S. G. Hans Jonas e a responsabilidade do homem frente ao desafio biotecnológico. 2009. 468f. Tese (doutorado) - Pós-graduação em Filosofia da Faculdade de Filosofia e Ciências Humanas da Universidade Federal de Minas Gerais, 2009.

FROGNEUX, N. Hans Jonas ou la vie dans le monde. Bruxelles: De Boeck, 2001.

JONAS, H. Memorias. Traducción de Illana Giner Comín. Madri: Editorial Losada, 2005.

JONAS, H. O princípio vida: fundamentos para uma biologia filosófica. Trad. Carlos Almeida Pereira. Petrópolis: Vozes, 2004.

JONAS, H. Pensar sobre Dios y otros ensayos. Trad. Angela Ackermann. Barcelona: Herder, 1998.

LOPES, W. E. S. Hans Jonas e a diferença antropológica: uma leitura da biologia filosófica. 2014. Tese (Doutorado em Filosofia) - Universidade Federal de Minas Gerais, 2014.

OLIVEIRA, J.; MORETTO, G.; SGANZERLA, A. Vida, técnica $e$ responsabilidade: três ensaios sobre a filosofia de Hans Jonas. São Paulo: Paulus, 2015.

\section{Contribuição dos autores:}

Os autores Leandro Sousa Costa e Leonardo Nunes Camargo contribuíram com a discussão, problematização, revisão e redação do artigo. Ambos aprovaram a versão final do texto.

Autor(a) para correspondência: Leandro Sousa Costa, Universidade Estadual do Paraná, R. Pernambuco, 858, Centro, CEP 87701-010, Paranavaí - PR, Brasil. leandro_kallas@hotmail.com 